\title{
"THE PENITENT WAG" E "THE FUNNY-MAN WHO REPENTED": DISCUTINDO TRANSPOSIÇÕES DO CONTO “O ENGRAÇADO ARREPENDIDO", DE MONTEIRO LOBATO
}

\author{
Rosemary de Paula Leite Carter* \\ Universidade Paulista
}

\begin{abstract}
Resumo: Este artigo objetiva discutir aspectos do cruzamento de duas transposiçôes para o inglês do conto "O Engraçado Arrependido" (1923) de Monteiro Lobato. Essa obra foi publicada como "The Penitent Wag" nos Estados Unidos em 1925 tendo outra transposição, em 1947, como "The Funny - Man Who Repented". Procuramos relevar as intervenções, manipulações e alterações realizadas nos dois textos de chegada por seus tradutores considerando, também, que as transposições aconteceram em momentos temporais distintos. As estratégias utilizadas nas duas versões apontam que ambos preocuparam-se em lapidar seus textos no intuito de ajustá-los às expectativas e vivências culturais do novo leitor, oriundo de outro sistema literário.
\end{abstract}

Palavras- chave: Monteiro Lobato. Transposição. Idioma Inglês.

\footnotetext{
" Graduação em Letras pela Pontifícia Universidade Católica de São Paulo e Mestrado em Letras: Língua Inglesa e Literaturas Inglesa e Norte-Americana pela Universidade de São Paulo (2000). Completou o Doutorado em Letras na Universidade Presbiteriana Mackenzie - SP (2012), com a Tese: Monteiro Lobato Acontece na América. É professora Visitante na Universidade Paulista. São Paulo, Brasil.E-mail:roseplc@terra.com.br
} 


\title{
"THE PENITENT WAG" AND "THE FUNNY- MAN WHO REPENTED": CROSS-EXAMINING THE TRANSPOSITIONS OF THE SHORT STORY "O ENGRAÇADO ARREPENDIDO" WRITTEN BY MONTEIRO LOBATO
}

\begin{abstract}
This article aims to cross-examine aspects of two transpositions, "The Penitent Wag" (1925) and "The Funny-Man Who Repented"(1947), of the short story "O Engraçado Arrependido" (1923), written by Monteiro Lobato. We sought to highlight the interventions, manipulations and alterations used by both translators when trying to mediate between languages and culture in order to fulfill the expectations of a new reader from another literary system.
\end{abstract}

Keywords: Monteiro Lobato. Transposition. English Language.

\section{Introdução à discussão}

Este artigo é um recorte, com adaptações, da minha tese de doutorado em Letras que aborda aspectos do cruzamento de duas transposições, "The Penitent Wag" e "The Funny-Man Who Repented", do conto "O engraçado arrependido" de Monteiro Lobato. O estudo da obra lobatiana encontra-se elaborado a partir das mais diversas perspectivas, entretanto pouco se conhece sobre as traduções para o idioma inglês da sua ficção para adultos. Pretendemos, neste artigo, esclarecer alguns aspectos que julgamos interessantes a partir de duas versões para o inglês do conto "O Engraçado Arrependido" (1923), de Monteiro Lobato. A primeira versão, conhecida até este momento, teve como título "The Penitent Wag", e foi publicada em Brazilian Short Stories, na Série Little Blue Books $n^{\circ} 733$, pela Haldeman-Julius Company em 1925. A segunda análise abordará "The Funny-Man Who Repented", nome atribuído ao conto em A World of Great Stories, pela Crown Publishers, em 1947.

O conto "The Penitent Wag", segundo uma nota de rodapé do crítico literário norte-americano Isaac Goldberg ${ }^{1}$ foi traduzido para 
o inglês por uma pessoa amiga de Monteiro Lobato, desconhecendo-se seu nome até os dias atuais. Já “The Funny-Man Who Repented" teve como tradutor o Professor do Queens College - EUA, Harry Kurz (1889-1973).

Discutiremos, aqui, efeitos de sentido e de procedimentos, como: intervenções, explicitações, omissões, acréscimos, e possíveis perdas e ganhos que o conto "O Engraçado Arrependido" (1923) veio a sofrer nessas duas transposições para o idioma inglês.

Pode-se já antecipar que a tarefa dos tradutores de Lobato ultrapassa a complexidade de qualquer trabalho tradutório visto que a obra lobatiana - como vem apontando sua melhor crítica - contém expressões correntes de sua época, provavelmente espelho da linguagem corriqueira no universo das fazendas e das pequenas cidades interioranas, o que poderá representar entraves até para um bom conhecedor de ambos os idiomas.

É este caráter tão profundamente brasileiro que tornará interessante discutir se a "imagem de Brasil" projetada por Lobato, no conto incluído na nona edição de Urupês (1923), ao menos aqui provisoriamente entendido como texto de partida, veio ou não a sofrer alguma repaginação nos mencionados dois textos de chegada.

Para que possamos melhor acompanhar a análise dessas duas transposições foi elaborado um quadro que apresenta os dois textos de chegada em inglês, dispostos ao lado do texto de partida. A coluna ML indica o texto de partida "O engraçado arrependido" presente em Urupês, nona edição, publicado pela Monteiro Lobato \& Cia. em 1923.

A letra G, no quadro, designa a transposição "The Penitent Wag", com tradutor(a) desconhecido(a) e foi publicada em Brazilian Short Stories, Little Blue Books no733 em 1925, com "Introdução" de Goldberg.

Já a letra K, refere-se à versão “The Funny - Man Who Repented" tendo Harry Kurz como tradutor, sendo publicada inicialmente em A World of Great Stories, em 1947.

Como por hipótese, $\mathrm{G}$ (tradutor desconhecido) pode ter realizado seu trabalho em qualquer momento entre 1918 (ano da publi- 
cação da primeira edição de Urupês) e 1925 (data do lançamento de Brazilian Short Stories nos Estados Unidos), levaremos em consideração que as ferramentas adotadas nas versões nessa época, baseavam-se mais na intuição, na cultura e nos conhecimentos do idioma de chegada dos tradutores, muitas vezes eles próprios, escritores. Tanto Kurz como a publicação em $\mathrm{G}$ não especificam qual edição do texto de partida foi fonte para respectivas transposições, portanto cotejaremos a edição de 1923, logo anterior à versão em inglês.

Com a publicação dos contos "The Penitent Wag", "Modern Torture" ("Um suplício moderno") e "The Plantation Buyer" ("O comprador de fazendas"), que também fizeram parte em Brazilian Short Stories (1925), Monteiro Lobato teve a oportunidade de inserir seu nome no mercado livreiro norte-americano. Lobato já era, naquela altura, mencionado no cânone nascente de escritores oriundos da América do Sul, em algumas obras e artigos do Professor e conceituado crítico literário Isaac Goldberg.

Quanto ao papel da tradução na construção do cânone literário, Bassnett (2003) argumenta que à medida que os Estudos de Tradução avançaram no mundo contemporâneo, também se colocaram em evidência questionamentos importantes sobre:

[...] as estratégias utilizadas pelos tradutores e as normas vigentes em determinado momento histórico, o discurso dos tradutores, os problemas da medição do impacto das traduções e, mais recentemente, os problemas relativos ao estabelecimento de uma ética da tradução (BASSNETT, 2003, p. 5-6).

É a partir de tais pressupostos que analisaremos alguns trechos das duas transposições mencionadas.

Análise de trechos das Transposições "The Penitent Wag" e The Funny - Man Who Repented

Como já explicitado, $\mathrm{G}$ refere-se ao texto (1925) com tradutor (a) desconhecido (a), e K é aquele transposto por Harry Kurz (1947). 


\begin{tabular}{|c|c|c|}
\hline ML & G & K \\
\hline $\begin{array}{l}\text { Francisco Teixeira de } \\
\text { Souza Pontes, galho } \\
\text { bastardo duns Souza } \\
\text { Pontes de trinta mil } \\
\text { arrobas afazendados } \\
\text { no Barreiro, só aos } \\
\text { trinta e dois anos de } \\
\text { idade entrou a pensar } \\
\text { seriamente na vida (p. } \\
\text { 23). }\end{array}$ & $\begin{array}{l}\text { Francisco Teixeira de } \\
\text { Souza Pontes, bastard } \\
\text { scion of a Souza } \\
\text { Pontes family, rich } \\
\text { planters of Barreiros } \\
\text { and owners of thirty } \\
\text { thousand "arrobas"* } \\
\text { of coffee, at thirty- } \\
\text { two years of age } \\
\text { began to take life } \\
\text { seriously (p.27). }\end{array}$ & $\begin{array}{l}\text { Francisco Teixeira } \\
\text { De Souza Pontes, } \\
\text { illegitimate scion of } \\
\text { a Souza Pontes who } \\
\text { owned some large } \\
\text { Barreiro plantations, } \\
\text { began to think } \\
\text { seriously on life only } \\
\text { when he reached his } \\
\text { thirty-second birthday } \\
\text { (p. 941). }\end{array}$ \\
\hline
\end{tabular}

O conto nomeado em ML como "O engraçado arrependido" (1923) foi transposto em G, por "The Penitent Wag”(1925) e, em K, por "The Funny-Man Who Repented"(1947).

A transposição do título inicial delineia maior profundidade semântica em G ("The Penitent Wag"), pois o termo em inglês "wag" sugere ao leitor um indivíduo gozador, contador de piadas que, eventualmente, poderia expor as pessoas ao ridículo, enfim, um "troçador". O conto de Monteiro Lobato primeiramente publicado na Revista do Brasil (Abril de 1917), tinha por título "A Gargalhada do Colector", privilegiava uma imagem "escancarada"do riso. Posteriormente, o conto veio a se chamar "O engraçado arrependido", mais próximo do adjetivo "funny" ou seja, divertido, forma mais contida, mantida no título dado por K: "The Funny-Man Who Repented".

$\mathrm{Na}$ obra de partida quanto nos textos de chegada, as expressões que qualificam a personagem título têm conotação religiosa: em $\mathrm{G}$, encontramos o adjetivo - "penitent" - e, em K, o verbo também de raízes religiosas - "to repent”- (arrepender-se).

Pode-se dizer que há um duplo sentido na mensagem do enunciado: o gozador estaria arrependido não da premeditação do "crime" contra o major, mas da escolha concretizada em seus anos 
juvenis, de cuja imagem tão fortemente consolidada na sociedade local, não conseguia se desvencilhar. Seria sempre considerado um palhaço ("clown") ou mero trocista ("wag"), que de "tanto fazer graça” não era levado a sério. O próprio título do conto já conduz o leitor à presença de um paradoxo, pois “indivíduos engraçados" tendem a ver os fatos da vida por uma óptica sem culpa, sem arrependimentos...

Em "The Funny-Man Who Repented", o texto inicia-se com letras maiúsculas que, coincidentemente, contempla o nome completo da personagem principal, diferentemente dos dois outros textos (ML e G), em que observamos o uso de maiúsculas na forma convencional, aplicadas somente à primeira letra de nomes e sobrenomes.

Ambas as transposições utilizam-se da palavra "scion" para caracterizar Francisco Teixeira de Souza Pontes, descendente de família abastada, mas descrito em ML como um "galho bastardo". O termo empregado ("galho") está ligado ao universo da agricultura, da lavoura o que foi seguido nas escolhas em $\mathrm{G} \mathrm{e} \mathrm{K}$, quando optaram por "scion".

$\mathrm{G}$ acrescenta um "s" à localidade mencionada no texto de partida: "Barreiros", ao invés de "Barreiro" em ML, no que não foi seguido por K, que é fiel ao texto de partida.

Para transpor a idéia de "afazendados". G credita um adjetivo à família Souza Pontes ao qualificá-la como "rich"; já K detalha "[...] Souza Pontes who owned some large Barreiro plantations". O termo "plantation", no idioma inglês, está ligado no imaginário norte-americano às terras do sul dos EUA: no século XIX, as fazendas sulistas eram descritas como "large plantations". Assim, a palavra "plantation" para o norte-americano, denota não só uma grande herdade como também um estilo de vida senhorial e patriarcal.

Em ML, a situação econômica da Família de Souza Pontes é indicada pelo segmento "Souza Pontes de trinta mil arrobas afazendados no Barreiro" e vale a pena observar como cada um dos tradutores transpôs a informação. 
Um dado que não está contido no texto original em ML é acrescentado por $\mathrm{G}$, ao relatar que a família Souza Pontes é detentora de trinta mil arrobas... "de café". O tradutor insere uma nota de rodapé, relatando que uma arroba seria o equivalente a 32 "pounds". Sabemos que a medida inglesa equivalente a um "Pound" é de aproximadamente 453,59 gramas; assim uma arroba seria o equivalente a 15 quilos, e 30.000 arrobas a 450.000 quilos, o que fornece ao leitor norte-americano uma ideia da riqueza da família Pontes.

Observamos que o Brasil, em 1925, projetava uma imagem agrária mundialmente forte calcada em seu carro chefe - as exportações do café - e provavelmente, na época, ser um fazendeiro de café no país seria sinônimo de riqueza.

Tanto a nota de rodapé como a palavra "café" estão ausentes no texto de partida, verificando-se, então, um acréscimo em G. Julgamos que essa intervenção possa ter ocorrido para conferir uma imagem abastada à família Souza Pontes.

Para Bassnett (2003, p.13) uma tradução não seria um mero "espelho" do texto original, mas este poderia sofrer uma "modificação" ou "alteração" em seu percurso, de acordo com as opções de escolha deixadas ao tradutor, para satisfazer as expectativas de seus leitores.

Já K não acrescenta notas de rodapé em nenhum trecho de seu texto, seguindo estritamente o texto de partida.

G mantém as arrobas (30.000) mencionadas em ML, ao contrário de $\mathrm{K}$, que as omite, numa manipulação do trecho. Essa informação que a nosso ver remete à ideia de "grandeza" e "poder" da família da personagem, perde-se no texto de $\mathrm{K}$.

Em ML, é forte a crítica do autor ao estilo de vida da personagem Pontes, que conseguira casa, vestuário e o mais, somente a custa de exibir-se com a sua "veia cômica", nunca tendo de fato se preocupado em buscar um trabalho sério.

Abaixo temos a descrição de como Pontes, até então, ganhara a vida... 


\begin{tabular}{|c|c|c|}
\hline ML & G & $\mathbf{K}$ \\
\hline $\begin{array}{l}\text { Como fosse de } \\
\text { natural engraçado, } \\
\text { vivera até alli à conta } \\
\text { de veia comica, e } \\
\text { com ella amanhára } \\
\text { casa, mesa, vestuario } \\
\text { e o mais.Sua moeda } \\
\text { corrente eram } \\
\text { micagens, pilherias, } \\
\text { anecdotas de inglez } \\
\text { e tudo quanto bole } \\
\text { com os musculos } \\
\text { faciaes do animal } \\
\text { que ri,vulgo homem, } \\
\text { repuxando risos } \\
\text { ou matracolejando } \\
\text { gargalhadas (p.23). }\end{array}$ & $\begin{array}{l}\text { A wag by nature, } \\
\text { up to that time he } \\
\text { had lived off his } \\
\text { comic strain and } \\
\text { thereby reaped board, } \\
\text { lodging, clothing and } \\
\text { all else. His currency } \\
\text { consisted of grimaces, } \\
\text { jokes, anecdotes } \\
\text { about Englishmen and } \\
\text { everything that tickles } \\
\text { the facial muscles of } \\
\text { the animal that laughs } \\
\text { commonly called } \\
\text { man, provoking } \\
\text { hilarity or raising } \\
\text { hearty guffaws } \\
\text { (p.27). }\end{array}$ & $\begin{array}{l}\text { A natural clown, he } \\
\text { had used his comic } \\
\text { gifts until then to } \\
\text { make his way and } \\
\text { provide him with } \\
\text { home, food, clothing, } \\
\text { and the rest. The } \\
\text { currency he used in } \\
\text { payment consisted } \\
\text { of funny -faces, } \\
\text { jokes, stories about } \\
\text { the English, and } \\
\text { everything calculated } \\
\text { to produce an effect } \\
\text { on the facial muscles } \\
\text { of the laughing animal } \\
\text { commonly called } \\
\text { man, by summoning } \\
\text { him to chortle or } \\
\text { break into guffaws } \\
\text { (p.941-42) }\end{array}$ \\
\hline
\end{tabular}

Considerando o trecho em ML, os tradutores recorrem a soluções diferentes à abertura do parágrafo ao apresentarem a personagem Pontes. Verificamos uma construção mais alongada em ML, "Como fosse de natural engraçado", em que se constata o acréscimo lexical com a conjunção "como", e o verbo no subjuntivo - "ser". Já em G, temos uma introdução mais concisa em que se lê "a wag by nature" com a retomada da expressão que dá título ao conto e reforça os sentidos nele embutidos. Em K, o termo "clo$w n$ " traz para o texto toda a carga semântica da expressão.

O verbo "amanhar", presente no texto de partida, está ligado ao mundo da lavoura, da labuta na terra, com conotação de esforço físico, representação ausente em G ("to reap") e em K ("to provide"). 
A expressão "moeda corrente" (ML) está transposta por “currency" em ambas transposições e, em $\mathrm{K}$, verificamos o acréscimo lexical com a expressão "in payment", em que o tradutor, num alongamento, reforça ao leitor desavisado a maneira como a personagem Pontes ganhava sua vida: sua moeda de troca era "fazer graça".

Já fazer "micagens" foi transposto em G por "grimaces" ("fazer caretas") e, em K, por "funny-faces". ML usa o verbo "bolir" ("mexer"); G utiliza-se do verbo "tickle", que acrescenta ao texto a ideia de "fazer cócegas", enquanto que em K constatamos uma perífrase para aproximar-se do texto de partida ("[...] and everything calculated to produce an effect on the facial muscles of the laughing animal commonly called man [...]").

Registramos, abaixo, um trecho onde Monteiro Lobato (ML) comenta sobre a Encyclopedia do Riso e da Galhofa de Eduardo Laemmert (1848):

\begin{tabular}{|c|c|c|}
\hline ML & $\mathbf{G}$ & $\mathbf{K}$ \\
\hline $\begin{array}{l}\text { Sabia de cór a } \\
\text { Encyclopedia do Riso } \\
\text { e da Galhofa, de Fuão } \\
\text { Pechincha a creatura } \\
\text { mais dissaborida } \\
\text { que Deus botou no } \\
\text { mundo; mas era tal } \\
\text { a arte do Pontes, } \\
\text { que as semsaborias } \\
\text { mais relamborias } \\
\text { ganhavam em sua } \\
\text { bocca um chiste raro } \\
\text { e os ouvintes }\end{array}$ & $\begin{array}{l}\text { He knew So-and-So's } \\
\text { "Encyclopedia of } \\
\text { Laughter and Mirth" } \\
\text { by heart-the most } \\
\text { mirthless creature } \\
\text { God ever made, but } \\
\text { such was Pontes } \\
\text { ability that he could } \\
\text { turn the most feeble } \\
\text { jokes into excellent } \\
\text { witticisms, to the } \\
\text { delight of his hearers } \\
\text { (p. 27). }\end{array}$ & $\begin{array}{l}\text { He knew by heart } \\
\text { the Enciclopedia } \\
\text { of Laughter and } \\
\text { Merriment by Fuao } \\
\text { Pechincha, the most } \\
\text { insipid author God } \\
\text { ever let into his } \\
\text { world; but Pontes' } \\
\text { art was so fine that } \\
\text { he the most pointless } \\
\text { tales received, when } \\
\text { recounted by him, a } \\
\text { special tang, enough }\end{array}$ \\
\hline $\begin{array}{l}\text { babavam de puro } \\
\text { goso (p. 23). }\end{array}$ & & $\begin{array}{l}\text { to make his listeners } \\
\text { froth at the mouth } \\
\text { with pure joy (p.942). }\end{array}$ \\
\hline
\end{tabular}


G e K dão diferentes soluções tipográficas à citação a respeito da Encyclopedia do Riso e da Galhofa em ML: ambos transpõem o título para o inglês. Entretanto K optou pelo "itálico" ao referir-se à obra Enciclopedia of Laughter and Merriment e G, pelo uso de aspas - "Encyclopedia of Laughter and Mirth".

Em G, o termo "mirthless" retoma a palavra "mirth" já presente na transposição do título do livro, acrescentando um traço de ironia ausente no texto de partida. Em K, a opção "insipid” precedendo o substantivo "author", por sua vez, mantém a etimologia ligada a "sabor" presente no texto de partida.

G e K transpõem a expressão "de cór”, presente no texto de partida, por outra equivalente no idioma de chegada: "by heart". $\mathrm{G}$ novamente investe em novos significados ao empregar "So and So's" (caso genitivo) que, com ironia, coloca o autor no anonimato: "So and So's Encyclopedia of Laughter and Mirth". Ao optar pela expressão "So-and-So's" equivalente ao vernáculo "fulano", "sicrano", G tanto pode espicaçar a curiosidade do leitor como, também, menosprezar a importância do autor do livro. No idioma inglês, como também no português, valer-se das expressões sicrano ou beltrano quando conhecemos o nome do indivíduo nomeado mas o omitimos, de certa forma diminuímos sua importância.

Valem aqui algumas considerações sobre a obra citada em ML. Eduardo Laemmert, sob o pseudônimo de Pafúncio Semicúpio Pechincha, lança a Encyclopedia do Riso e da Galhofa pela sua própria editora em 1848. ML (1923) aponta que a enciclopédia fora escrita por "Fuão Pechincha", numa possível referência à Pafúncio Semicúpio Pechincha (Eduardo Laemmert), o organizador da Encyclopedia do Riso e da Galhofa (1848); K é fiel ao texto de partida: a relação de "So and So" é com um óbvio pseudônimo, e não com um nome próprio...

G ao caracterizar o autor da Enciclopédia do Riso e da Galhofa como "the most mirthless creature God ever made", constrói um jogo interessante e irônico com a transposição do título Encyclopedia of Laughter and Mirth, negando a seu autor ("mirthless") a característica que nomeia sua obra. 
Relativamente ao autor ao qual a enciclopédia é atribuída, o texto de partida o nomeia como Fuão (fulano, sicrano ou beltrano). Em inglês, haveria a opção da transposição para "John Doe", ou "Simpleton", expressões que indicariam uma pessoa sem nome, um "Zé ninguém”. No entanto, G e K optaram por não transpor a palavra "Fuão" e tampouco se valeram de uma nota de rodapé, que poderia aproximar o termo ao imaginário do leitor norte-americano. Não se encontra, também, uma nota dos tradutores para mencionar a ligação entre o importante editor alemão Laemmert - já estabelecido no Brasil no século XIX -, e a inserção do sobrenome "Pechincha" ao texto de chegada, o que faz com que o leitor norte-americano não "saboreie" o detalhe sutil presente em ML.

$\mathrm{G}$ optou, como observado, por não individualizar a autoria dessa obra e K, por não traduzir por completo seu autor (Pechincha), que consta no texto de origem de 1923. A palavra "Pechincha", que em inglês significa "bargain", não está de todo longe do adjetivo "barato", e não deixa de ser uma alusão divertida e de remeter a uma caricatura da personagem. A nosso ver, o fato de G e K optarem pela não transposição do termo conteve o sorriso malicioso...

Sobre o assunto da supressão de termos, recurso engendrado por G e K nesse trecho, temos a opinião de Campos (2004) ao mencionar que "a omissão de detalhes do texto de partida, quando na sua transposição para outro idioma, deve-se a alguns fatores”. Campos aponta a existência de dois tipos de tradução como consequência de textos difíceis, ainda que não de todo intraduzíveis, o que vem determinar dois tipos de tradução a "integral", na qual se traduzem todos os itens, todas as palavras e expressões; e a "parcial", na qual deixam de serem traduzidas algumas partes do texto de origem (CAMPOS, 2004, p.31).

Campos (2004) menciona a tradução dita "oblíqua":

Quando as duas línguas são de troncos linguísticos diferentes, como o português, que é uma língua neo-latina, e o inglês, que é anglo-germânica, a tradução costuma distanciar-se 
bastante da forma do original, tornando-se assim menos literal, menos palavra por palavra, e mais "oblíqua", como se diz. Mas também a diferença de culturas, entre as dos falantes naturais de uma língua e a dos falantes naturais da outra, contribui para a obliquidade de uma tradução (CAMPOS, 2004, p.33).

Como um exemplo, em $\mathrm{G}$ temos a omissão de "babavam de puro gozo" presente em ML, substituído por "the delight of his hearers", em que o termo "delight" eleva a expressão do riso, ao omitir detalhes físicos. Tipograficamente "Fuão" possui um til em ML, que é omitido em $\mathrm{K}$ e em $\mathrm{G}$.

As "semsaborias e relamborias", em ML, foram transpostas, em G, para"the most feeble jokes" e em K, para "the most pointless tales", numa interpretação em que cada tradutor classifica de uma maneira o gênero textual a que se refere ML. "Jokes" (em G) significariam "piadas sem graça” e "tales"- contos ou histórias, em K.

O substantivo "chiste" presente em ML foi transposto em G como "witticism", que eleva a qualidade do "ser engraçado" ao remeter ao termo "wit" (atitude intelectual e abstrata) e em K, como a "special tang", que remete ao mundo olfativo, mantendo assim a sensação física do gozo da ironia expressa em K: "his listeners froth at the mouth with pure joy".

ML completa a descrição da personagem Francisco Pontes, ao mencionar ao leitor que os "ouvintes babavam de puro goso" ao ouvir seus gracejos; a opção foi modalizada em $\mathrm{G}$, pois ao invés de utilizar-se do verbo "babar", escreve: "to the delights of his hearers".

A seguir, apontamos as escolhas lexicais dos tradutores para verbos onomatopaicos: 


\begin{tabular}{|c|c|c|}
\hline ML & $\bar{G}$ & $\mathbf{K}$ \\
\hline $\begin{array}{l}\text { Também grunhia de } \\
\text { porco, cacarejava } \\
\text { de gallinha, coaxava } \\
\text { de untanha, ralhava } \\
\text { de mulher velha, } \\
\text { choramingava de } \\
\text { fedelho, silenciava de } \\
\text { deputado governista } \\
\text { ou perorarava de } \\
\text { patriota em sacada (p. } \\
\text { 24). }\end{array}$ & $\begin{array}{l}\text { He also grunted } \\
\text { like a pig, cackled } \\
\text { like a hen, croaked } \\
\text { like a toad, scolded } \\
\text { like an old woman, } \\
\text { whimpered like a } \\
\text { baby, enjoined silence } \\
\text { like a Representative } \\
\text { or speechified like } \\
\text { a patriot at a street } \\
\text { meeting (p. 27-28). }\end{array}$ & $\begin{array}{l}\text { He could also grunt } \\
\text { like a pig, cackle like } \\
\text { a hen, croak like a } \\
\text { toad, scold like an } \\
\text { old woman, whimper } \\
\text { like a crybaby, call } \\
\text { for silence like a } \\
\text { congressman in } \\
\text { power, or harangue } \\
\text { like a patriot on the } \\
\text { balcony (p. 942). }\end{array}$ \\
\hline
\end{tabular}

Em ML, são vários os verbos onomatopaicos: grunhir, cacarejar, coaxar; os verbos estão no "Pretérito Imperfeito" assim como os outros verbos do parágrafo: ralhava, chorava, silenciava e perorava.

G utiliza-se do Simple Past Tense e K opta pelo verbo modal "could" juntamente com a "base form" dos verbos: "grunt", "cackle”, "croak”, "scold”, “whimper”, "call for silence” (num alongamento) e "harangue". Os verbos no idioma de chegada "grunt", "cackle", "croak" - são igualmente onomatopaicos. K, ao empregar o modal "could", explicita que a personagem Pontes demonstrava, também, a habilidade de "grunhir" como um porco (se assim o desejasse).

Já nos textos em ML e em G, Pontes "grunhia de porco" (como na discrição de um hábito, e não de uma habilidade), o que vem ao encontro da introdução do parágrafo da língua de partida, que explicita que Pontes "era de natural engraçado", e cuja graça constituía-se, também, em saber imitar animais.

Em ML, o espaço em que a personagem Pontes perorava era semi-doméstico: a sacada de uma casa, dimensão mantida em $\mathrm{K}$ ("balcony”), mas que em G se transforma em um comício na rua "street meeting", numa manipulação do trecho. 
A transposição da palavra "fedelho", em G, é desmarcada ("baby”) e já em K, é marcada ("crybaby”) aproximando-se da conotação de um bebê "chato e chorão" ("a crybaby"). A palavra "fedelho" remete em português, também, à imagem de uma criança pequena, não necessariamente a de um bebê como os dois tradutores classificaram.

Abaixo, constatamos um exemplo da manipulação do texto de partida, pelo tradutor em G.

\begin{tabular}{|l|l|l|}
\hline \multicolumn{1}{|c|}{ ML } & \multicolumn{1}{|c|}{ G } & \multicolumn{1}{c|}{ K } \\
\hline $\begin{array}{l}\text { Que vozeio de bipede } \\
\text { ou quadrupede } \\
\text { não copiava elle às } \\
\text { maravilhas, quando } \\
\text { tinha pela frente um } \\
\text { auditorio predisposto? } \\
\text { (p.24). }\end{array}$ & $\begin{array}{l}\text { What two-legged } \\
\text { or four-legged hum } \\
\text { of voices did he not } \\
\text { mimic to perfection as } \\
\text { long as he had before } \\
\text { him an audience } \\
\text { well equipped with } \\
\text { those "muscles of } \\
\text { mirth" invented by } \\
\text { our talented authoress } \\
\text { Albertina Bertha? } \\
\text { (p.28). }\end{array}$ & $\begin{array}{l}\text { When he had before } \\
\text { him a favorable } \\
\text { audience, what cry of } \\
\text { could he not imitate to } \\
\text { perfection? (p.942). }\end{array}$ \\
\hline
\end{tabular}

Em G, o termo bípede foi transposto por "two-legged" e quadrúpede por "four-legged"; já em K temos "biped" e "quadruped”, o que legitima Pontes como excelente imitador não só de tipos humanos ("ralhava de mulher velha...") do quadro anterior, como de animais....

Nessa passagem $G$, numa manipulação lexical, acrescenta outros elementos ao texto de chegada ao adicionar o nome da escritora Albertina Bertha. Esse apontamento merece um parêntesis, pois a autora é considerada de vanguarda nas Letras brasileiras ${ }^{2}$. Sua obra colocou em destaque assuntos "tabus" como o adultério feminino e a sexualidade das mulheres provocando controvérsias na época. 
Na nona edição do conto "O engraçado arrependido" em Urupês (1923), no quadro acima, Albertina Bertha não é mencionada. Entretanto, na transposição norte-americana de 1925, em G, o nome de Albertina Bertha é inserido acompanhado por adjetivações como "talented authoress".

Quando publicado em 1917 com o título "A Gargalhada do Colector", o texto mencionava o nome da escritora, mas com seu "pré-nome" abreviado: "Sra. A. Bertha", fato que, como observado em Martins (1998, p.75), gera um trocadilho. A inicial “A”, em 1917, foi substituída por “Albertina”, em G, figurando assim na ficção norte-americana a referência à autora brasileira, com todas as suas letras. Ao acrescentar o adjetivo "talented" ao trecho, num alongamento, G (1925) não apenas qualifica a escritora como também universaliza sua avaliação a respeito da autora, ao adicionar o adjetivo possessivo "our”, antes da sua adjetivação ("our talented authoress"). G, assim, conserva a menção e o cotejo à alegria, o que parece ter sido sublinhado na versão do conto de 1917, intitulado "A gargalhada do colector".

Segundo Arrojo (2007, p.76) cada tradução: “[...] exige do tradutor a capacidade de confrontar áreas específicas de duas línguas e duas culturas diferentes, e esse confronto é sempre único, já que suas variáveis são imprevisíveis". Desse modo os dois tradutores ao confrontarem o texto de partida, ora optam por escolhas semelhantes ora se utilizam de manipulações e intervenções, que nada mais são do que frutos do produto de suas leituras individuais do texto.

Escolhemos um trecho, a seguir, onde se constata a presença de um falso cognato: 


\begin{tabular}{|l|l|l|}
\hline \multicolumn{1}{|c|}{ ML } & \multicolumn{1}{c|}{ G } & \multicolumn{1}{c|}{ K } \\
\hline $\begin{array}{l}\text { O coronel, depois de } \\
\text { ouvir-lhe attentamente }\end{array}$ & $\begin{array}{l}\text { The Colonel, after } \\
\text { listening attentively to }\end{array}$ & $\begin{array}{l}\text { After listening } \\
\text { attentively to his }\end{array}$ \\
\hline $\begin{array}{l}\text { as allegações, } \\
\text { conclusas pelo } \\
\text { pedido de um lugar } \\
\text { de capataz, explodiu } \\
\text { num ataque de } \\
\text { hilaridade: - O Pontes } \\
\text { capataz! Ih! Ih! Ih! } \\
\text { (p. 30). }\end{array}$ & $\begin{array}{l}\text { his reasons, ending up } \\
\text { with the offer to take } \\
\text { on the job as overseer } \\
\text { on the farm, exploded } \\
\text { in a fit of laughter. } \\
\text { "Pontes overseer! He! } \\
\text { he! he!" (p. 32-33). }\end{array}$ & $\begin{array}{l}\text { statements, followed } \\
\text { by the request to get } \\
\text { the foreman's place, } \\
\text { the Colonel exploded } \\
\text { in a hilarious burst, }\end{array}$ \\
"Pontes the foreman! \\
Sh! Sh! Sh! (p. 945).
\end{tabular}

Verificamos que nessa passagem ML refere-se à figura do "coronel", senhor de terras - figura folclórica no imaginário dos brasileiros - e que possui uma conotação secular de poder monetário e político. Tanto $\mathrm{G}$ como $\mathrm{K}$ transpõem o termo de forma errônea, ou seja, referem-se ao fazendeiro como um homem do exército: "a Colonel" (um falso cognato), o que não condiz com o texto de partida e faz com que se perca a conotação nas entrelinhas dessa figura folclórica, um verdadeiro "manda-chuva", tal seu poder no Brasil patriarcal e agrário.

A onomatopeia que configura uma risada - "Ih!Ih! Ih!, em ML, é transposta por "He!he!he!" em G e, em K, por "Sh"!sh! sh", numa provável aproximação com o novo leitor, de outro idioma e cultura, em datas distintas.

\section{Considerações Finais}

A primeira transposição publicada em 1925 revela uma aproximação com o inglês britânico, pois a Europa (Inglaterra e França) exercia, nos primeiros acordes do século XX, uma influência marcante nas Américas. Já em 1947, após a vitória dos aliados na segunda grande guerra, os EUA emergem como uma das "super- 
-potências" e o "American way of life" transforma-se em um dos ditames do mundo ocidental, com sua informalidade e coloquialismo.

Desse modo G (1925), ao delinear a personagem Pontes ao leitor, pondera que: "He [...] enjoined silence like a representative or speechified like a patriot at a street meeting" (1925, p.27-8). Já em K, temos: "He could [...] call for silence like a congressman in power [...] (1947, p.942). Observamos que $\mathrm{G}$ opta pela palavra "representative" enquanto K escolhe "congressman", termo ligado à vivência política do leitor norte-americano. Um antigo provérbio inglês seria "That's old as the hills, Pontes" (1925, p. 37) que foi transposto em K de uma forma mais informal e moderna: "That's an old joke, Pontes" (1947, p.947). Em G, observamos "Hold on man, you'll make me gag”! (1925, p.29) e, em K, “Stop, man, you're killing me!" (1947, p.943), em que o auxiliar no "Simple Future Tense" ("will") foi substituído pelo "Present Continuous"; e a expressão inglesa "you make me gag" transposta pela expressão bem coloquial: "you're killing me!"

Ainda em relação à época e seu linguajar, temos em $\mathrm{G}$ a expressão "federal collector's office" que, em K, é apresentada como "federal internal revenue office". A palavra "revenue" sinaliza um jargão de cunho financeiro utilizado nas empresas corporativas e no governo, principalmente após a segunda grande guerra.

Verificamos que em sua transposição Kurz se utilizou de um maior número de palavras em relação aos outros dois textos como, também, de um menor número de parágrafos em relação ao texto de origem e ao texto em $\mathrm{G}$, o que reforça o caráter discursivo de cada um dos tradutores frente ao texto de origem.

Em geral, tanto o (a) tradutor (a) desconhecido (a) em G como Kurz, em seus papéis de leitores do texto de partida e produtores do texto de chegada, preocuparam-se em detalhar elementos próprios de nossa cultura e vivências para o leitor norte-americano, vindo ao encontro das demandas desse novo público. Assim converteram medidas de pesagem, acrescentaram dados como "café" ao texto no afã de fornecer a dimensão da riqueza da família de Pontes; modificaram, também, a onomatopeia do riso expressa 
no texto de origem, para atender as expectativas do leitor norte-americano.

De acordo com a argumentação de Arrojo (2007, p.44), essas ferramentas vêm ao encontro das opções deixadas ao tradutor, pois:

\begin{abstract}
[...] nossa visão de qualquer texto, poético ou não, será fiel não ao texto "original", mas àquilo que consideramos ser o texto original, àquilo que consideramos constituí-lo, ou seja, à nossa interpretação do texto de partida, que será, como já sugerimos, sempre produto daquilo que somos, sentimos e pensamos.
\end{abstract}

Por fim verificamos que os dois tradutores procuraram respeitar o texto de chegada em suas transposições não deixando, entretanto, de marcar seu(s) texto(s) com uma releitura pessoal. Foi constatado que em algumas passagens os tradutores alongaram sentenças, acrescentaram informações, adicionaram nomes próprios, adjetivaram a fim de explicitar detalhes que talvez achassem de difícil compreensão para o leitor de outro sistema literário e com outra bagagem cultural.

\title{
Notas
}

1. GOLDBERG, Isaac (1887-1938). Importante figura na introdução do nome de Monteiro Lobato e de algumas de suas obras nos EUA. Goldberg teve publicado alguns artigos seus na Revista do Brasil.

2. STOCKLER, Albertina Bertha de Lafayette (1880 - 1953). Escreveu Exaltação (1916), objeto de polêmicas ora de aplauso e entusiasmo - caso do crítico Araripe Junior - ou de crítica, como em Lima Barreto e Anna Ribeiro de Goés Bittencourt (Liga Católica das Senhoras Baianas). 


\section{Referências}

ARROJO, Rosemary. Oficina de Tradução. A teoria na prática. $5^{\text {a }}$ ed. São Paulo: Ática, 2007.

BASSNETT, Susan. Estudos de Tradução. Fundamentos de uma Disciplina. Trad. Vivina de Campos Figueiredo. Revisão Ana Maria Chaves. Lisboa: Fundação Calouste Gulbenkian, 2003.

CAMPOS, Geir. O que é Tradução? São Paulo: Brasiliense, 2004.

GOLDBERG, Isaac. (Org.). Brazilian Literature. (with a foreword by John D. M. Ford). New York: Alfred Knopf Inc.: September, 1922.

. The Spirit of Brazilian Literature. Little Blue Books $\mathrm{n}^{0}$ 646. Girard, Kansas: Haldeman Julius Company, 1924.

. "Um novelista do Nacionalismo Brasileiro". In: "Notas do Exterior". $\overline{R e v i s t a}$ do Brasil. Anno VI. Vol. XVIII, nº 72, Dezembro de 1921, p.377-380.

. "Renascença literária Norte-Americana". In: "Notas do Exterior". $\overline{R e v i s t a}$ do Brasil. $\mathrm{n}^{\circ}$ 103, Julho de 1924, p.276-8.

. "A Actual Novella Americana". In: "Notas do Exterior". Revista do Brasil. Anno IX. Vol. XXVII. no 105, Novembro de 1924, p. 281-3.

HAYDN, Hiram e COURNOS, John. A World of Great Stories. New York: Crown Publishers, 1947.

HAYDN, Hiram e COURNOS, John. A World of Great Stories.115 stories, the best of modern literature. $2^{\mathrm{a}}$ ed. New York: Gramercy Books, 2003.

LOBATO, Monteiro. "The Penitent Wag". Tradutor desconhecido. In: Brazilian Short Stories. (Introd. Isaac Goldberg). Little Blue Books $\mathrm{n}^{0}$ 733. Kansas: Haldeman - Julius Company, 1925. 
. "The Funny - Man Who Repented". Tradução de Harry Kurz. In: $A$ World of Great Stories $1^{a}$ ed. New York: Crown Publishers, 1947 e New York: Gramercy Books, Random House, Inc., 2003.

. "The Funny - Man Who Repented". Tradução de Harry Kurz. In:

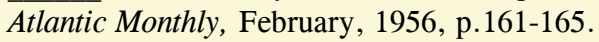

. Urupês. $9^{\mathrm{a}}$ ed. São Paulo: Monteiro Lobato \& Cia., 1923.

MARTINS, Milena Ribeiro. Quem conta um conto... aumenta, diminui, modifica. O processo de escrita do conto lobatiano. Dissertação (Mestrado) Instituto de Estudos da Linguagem. 1998, 129 f. Campinas, SP: Universidade Estadual de Campinas, 1998.

Recebido em: 12/08/2015

Aceito em: 06/10/2015 